\title{
(In)civility and adolescents' moral decision making online: drawing on moral theory to advance digital citizenship education
}

\author{
Tom Harrison $^{1}(1)$. Gianfranco Polizzi ${ }^{1}[$
}

Received: 30 April 2021 / Accepted: 10 August 2021 / Published online: 17 September 2021

(c) The Author(s) 2021

\begin{abstract}
This article draws on moral theory to advance digital citizenship education and explore how adolescents aged 13-16 make decisions when confronted with incivility, such as cyberbullying, on social media. Given the extent to which digital citizenship education may be approached in line with deontological (rules), utilitarian (consequences) and/or virtue ethical (character) theories, we argue that it is important to know which of these underpin adolescents' moral decision making online. To address this question, this article reports findings from a survey completed by 1947 13-16 year olds in England. Chi-square tests, binary logistic regressions and other exploratory analysis showed that most 13-16 year-olds use virtue ethical reasons to justify moral actions. We conclude that if online incivility is to be reduced, policymakers, educators and parents should focus more on virtue- and character-based approaches to digital citizenship education.
\end{abstract}

Keywords Adolescents $\cdot$ Moral decision making $\cdot$ Social media $\cdot$ Incivility $\cdot$ Moral theory $\cdot$ Deontology $\cdot$ Utilitarianism $\cdot$ Virtue ethics

\section{Introduction}

The question of whether the Internet contributes to or diminishes human flourishing - our ability as human beings to live well and thrive both individually and collectively (Jubilee Centre, 2017) - has been central to many academic and other publications since the technology was invented decades ago. Recently, Sir Tim Berners-Lee, credited with inventing what is known as the Web, has spoken about his hope that the technology can improve the world, yet acknowledged that "it's understandable that many people feel afraid and unsure if the Web is

Tom Harrison

t.j.harrison@bham.ac.uk

1 School of Education, University of Birmingham, Birmingham B15 2TT, UK 
really a force for good" (World Wide Web Foundation, 2019, para. 4). Sir Berners-Lee's assessment is not surprising given the prevalence of media, academic, policy and lay commentators who point out online harms and moral misdemeanors as an indication that using the Internet has made us increasingly unkind and uncivilized (see, e.g., Cocking \& van den Hoven, 2018). However, the Internet is also a positive addition to our lives as it presents considerable opportunities for learning, socializing, participation and entertainment (Livingstone et al., 2018).

For good or for bad, we live in societies that are increasingly saturated with digital technologies. Amid concerns about the risks that the Internet presents, policymakers in the UK have been discussing solutions, including the regulation of online platforms (UK Government, 2019) and the promotion of digital literacy, understood as the functional and critical skills and knowledge that users need to use digital technologies (Polizzi, 2020). However, to inform new policy and educational practice, we also need to know what informs individuals' moral decision making online, and particularly in relation to issues of (in)civility such as cyberbullying. Addressing this question, which has remained underresearched, is the purpose of the research reported in this article. This question is important not only for promoting what is commonly called digital citizenship education - the teaching of how to use digital technologies responsibly to participate in society (Ribble, 2007) - but also for understanding how moral theory should underpin this form of education.

We commenced our study with a belief that adolescents' online actions may be guided by reasons that align with deontological (following rules), utilitarian (evaluating consequences), and/or virtue ethical (deploying character virtues such as honesty and compassion) moral theories. It was not our contention that adolescents explicitly think about these moral theories when interacting with someone online. Rather, the idea was that these moral theories might be helpful for understanding moral decision making online. The aim of our research was therefore to explore the moral reasons that 13-16 year-olds use to justify the decisions they make when faced with a dilemma relating to online (in)civility. Surprisingly, there has been a dearth of academic literature addressing this important question.

This article fills this gap by reporting findings from a survey conducted with 1947 13-16 year-olds in England. The research focused on first finding out if the participants were more likely to make morally engaged or morally disengaged actions (Bandura, 1999) when presented with an instance of online incivility that targets a classmate. After this initial analysis had been conducted we then looked at those who gave a morally engaged response and sought to find out if this decision was informed predominantly by rules (deontological reasons), consequences (utilitarian reasons) or character (virtue ethical reasons). A better understanding of whether, how and why adolescents take moral actions online is crucial if we are to target educational policy and practice promoting digital citizenship education in order to address issues of online incivility that undermine our collective wellbeing, happiness and flourishing. The article starts with highlighting research relating to online incivility, showing why the study is significant. 


\section{Theoretical background}

\section{1 (In)civility, social media and adolescents}

Most adolescents in the UK use social media, understood by Ofcom (2020) as networking systems that include platforms like Facebook and Instagram as well as messaging services like WhatsApp. According to Ofcom (2020), "by the age of 13 (the minimum age restriction on most social media platforms) more than half have a profile; and by the age of 15, almost all have one" (p. 19). WhatsApp, for example, is used by $62 \%$ of 12-15 year-olds, who also use Facebook (69\%), Snapchat (68\%) and Instagram (66\%) (p. 20). Social media are designed to afford users the ability to communicate with others and act not just as consumers but as producers of information. This allows adolescents to benefit from using the Internet for gaming, socializing and studying, among other activities. However, it also increases risks of online abuse (e.g., cyberbullying, trolling, sexting, online humiliation, revenge porn) to which they might be exposed. Given the level and potential severity of these risks, it is not surprising that the issue of online (in) civility has attracted much attention in recent years.

Civility can be broadly defined as "the codes of behavior that allow us to share public spaces" (Griffith et al., 2011, p. 10). The question of whether it applies to public contexts of collective resistance that rely on political dissensus is beyond the scope of this article. Rather, we are concerned with online incivility - which we define broadly as the use of the Internet to bully, hurt or abuse others - in relation to how adolescents use social media on a daily basis. A new language has grown up to describe specific types of online incivility (including terms such as doxing, dogpiling, flaming and fraping) that can have serious repercussions on the wellbeing of young people. This is why, since the 1990s commentators have charted a litany of teenage suicides (such as those of Tina Meier, Tyler Clementi and Amada Todd) that are linked to online abuse. Similarly, Cocking and van den Hoven (2018) describe in their book "Evil Online" the worst aspects of the Internet through stories of online abuse.

Research into online civility shows why this is an issue that requires attention from academics, policymakers, educators and parents alike. Reported rates of online incivility vary across studies depending on how it is defined and on the age of respondents (Whittaker \& Kowalski, 2014). Most studies show that between $10 \%$ and $40 \%$ of children and young people report being victims of cyberbullying, both in the UK and elsewhere (see Patchin \& Hinduja, 2015). Those who experience online abuse are 2.3 times more likely to self-harm and 2.5 times more likely to attempt suicide than those who do not (John et al., 2018). Ofcom (2020) found that three out of ten 8-15 year-olds think that "people are mean to each other on social media all or most of the time" (p. 21). More problematically, "while almost half of $12-15 \mathrm{~s}$ feel it is not $\mathrm{OK}$ for people to ... say what they want online if it is hurtful to others, three in ten are unsure, suggesting a degree of uncertainty around what is and isn't acceptable" (p. 21). It is not surprising therefore that academic research on how to deal with online abuse such as cyberbullying is on the 
increase (Smith \& Berkkun, 2017). This and similar research has informed policy documents in the UK about the impact of the Internet on young people's wellbeing, mental health and potential to flourish online (see, e.g., UK Government, 2019). Relatedly, it is the backdrop against which we conducted our research to inform educational approaches that might reduce online incivility and abuse.

\subsection{Moral decision making online}

Most adolescents in the UK make moral decisions everyday about how they behave online and what they post, share, like and comment on (Harrison, 2016b). Do they decide to forward an unkind post or report it, or to post an unfavorable picture or trash it? In practice, moral decision making (i.e., the decisions that individuals make to navigate the ethical implications of a given situation) has many faces to it. Sometimes it will be instant, other times it will be muddled and extended over time. Sometimes it will be undertaken more consciously, and other times more implicitly (Haidt \& Joseph, 2008). Moral decisions depend on context - they are influenced by perceptions of situations, who is involved, personal values and judgements, rules and consequences. Of course, however, not all decisions will be acted upon. Awareness of what the right course of action might be does not necessarily equate with taking that course of action, or any action at all.

In this article we draw on Bandura's (1999) theory of moral disengagement (which refers to the belief that the ethical features of a situation do not apply to oneself) to classify how adolescents respond to incivility online in either morally engaged or morally disengaged ways. According to Bandura, individuals separate their thoughts and actions in order to rationalize and justify their engagement in (im) moral acts. Bandura (2001) argues that the moral self is "embedded in ... self-regulative mechanisms" (p. 102). As explained later in the article, we used the concepts of moral engagement and disengagement to classify how 13-16 year-olds respond to coming across a post on social media that is unkind to one of their classmates. There is a debate in the literature about how inaction when witnessing an immoral act, the so-called bystander effect, should be classified. Some (e.g., Kyriacou et al., 2018; Machakova et al., 2018) have categorized bystander behavior online as hostile, defensive, or passive. Others like DeSmet et al. (2015) have categorized it, more simply, as either "positive" (e.g., defending victims, reporting abuse) or "negative" (e.g., passive or reinforcing hostile behavior). In short, while bystander behavior (when it is not defensive) can be either hostile (e.g., posting a comment online in support of an abusive post) or passive (doing nothing), not just the former but also the latter may be framed as something questionable, since they both fuel online incivility and abuse such as cyberbullying. This is why Benzmiller (2013) has even argued that the passive role of bystanders online should be criminalized. It is worth noting, however, that bystander behavior online is amplified by the nature of the digital environment and the affordances of digital technologies, including the fact that the Internet is under-regulated and allows online anonymity (Runions \& Bak, 2015).

In our study we were primarily interested in how 13-16 year-olds justify their morally engaged or disengaged actions, and how their reasons align with different 
moral theories. This article draws on the three most prominent moral theories to categorize moral decision making as underpinned by reasons that may be: 1) deontological (i.e., based on the recognition of normative rules as to what the right behavior should be), 2) utilitarian (i.e., based on the idea that the moral value of an action depends on the consequences of that action), and/or 3) virtue ethical (i.e., based on the belief that individuals should possess virtues such as honesty and compassion and know, as theorized by Aristotle, how to deploy the right virtues depending on context) (LaFollette and Persson, 2013). Traditionally, research informed by moral theory, which is often treated monolithically and with little attention to virtue ethics (Frímannsson, 2021), has prioritized investigations of deontological and utilitarian judgments by examining responses to moral dilemmas designed to pit one course of action against another (e.g., Bartels $\&$ Pizarro, 2011). The classic example involves the task of presenting participants with hypothetical scenarios such as that of a runaway trolley that will kill five people unless participants intervene by causing the death of another individual (Foot, 1978). Recently, there has been a resurgence in contemporary moral philosophy of virtue ethics widely believed to be inspired by Elizabeth Anscombe (1958). Advocates for virtue ethics claim that this brings more attention to how character and virtues influence individuals' decisions and actions and, as such, is more contextually sensitive (Kristjánsson, 2015). Importantly, the three moral theories above are not mutually exclusive, which raises the question of what their interplay consists of in the context of how adolescents use digital technologies. An understanding of how these theories play out in the real world of 13-16 yearolds making decisions when confronted with online abuse may inform what educators, parents and policymakers can do to reduce online incivility. It can help them decide if they should place more emphasis on imposing rules that limit adolescents' use of the Internet, on encouraging them to think about the consequences of their own actions, and/or on cultivating virtues such as compassion, wisdom and honesty.

A few studies informed by moral psychology have explored the extent to which users make morally engaged or disengaged decisions online, depending on their emotions or on their perceptions of the ethical features of different online contexts (D'Errico \& Paciello, 2018; Ge, 2020). What is lacking, however, is research exploring moral decision making online through a multifaceted moral theoretical lens. Indeed, we do know to what extent adolescents make decisions online that can be classified against the moral theories of deontology, utilitarianism and virtue ethics. There is some research that has investigated online interactions through one of these lenes. For example, adopting a deontological frame, Selwyn \& Aagaard (2021) have researched how countries impose rules on smartphone use in schools, while others have considered the rights and duties of Internet users (e.g., Lievens 2011; Lyu 2012). The preponderance of deontological approaches is not surprising, since Kantianism (which is what deontology stems from) is the moral theory of choice in many areas of applied ethics. Meanwhile, articles that explore happiness or wellbeing as a consequence of online interactions, thus adopting consequentialist lines of enquiry, are also common (e.g., Stauffer et al., 2012). Recently, furthermore, there has been more focus on virtue ethics, with Harrison (2016a; 2021) and Vallor 
(2016), amongst others, stressing the importance of adopting such a focus when researching digital technologies.

Despite calls that ethics in everyday life should not be codified into discreet moral theories (Williams, 1985), researchers rarely draw on more than one moral theory when considering moral decision making online. Of all the studies that we assessed, only one conducted by Cheolo Yoon (2011) proposes a moral decision-making model for the Internet that is based on five moral philosophies - justice, relativism, egoism, deontology and utilitarianism. Yoon draws on Reidenbach and Robin (1990) to define 1) justice as the principles that promote equality, 2) relativism as morality that is relative to culture, 3) egoism as the idea that the self should be the goal of one's own actions, 4) deontology as the expectation that acts are inherently right or wrong, and 5) utilitarianism as the conviction that moral action should be determined solely by its contribution to happiness (p. 2402). Yoon's model, tested among university students in South Korea, suggests that their moral judgments align with these theories, affecting, in turn, their behavioral intentions. Except for his study, however, there is a lacuna in the literature, which is addressed by the present study.

\subsection{Moral decision making and digital citizenship education}

What is clear from the literature is that there is a lack of research, both in the UK and elsewhere, on adolescents' moral decision making online, and particularly in relation to (in)civility on social media. Despite this gap in the literature, we know that many schools, in practice, employ strategies to teach young people elements of moral education as part of what is commonly known as digital citizenship education (DCE) and in ways that are coupled with digital literacy education. Although digital citizenship is a contested term, it is often understood as the wise and responsible use of digital technologies in line with norms of appropriate behavior, and with a view to participating in society (Ribble, 2007). A recent OECD report (Burns \& Gottschalk, 2020, p. 46) shows that promoting DCE is perceived across multiple countries in the world as the most pressing global challenge of the digital age, over both the tackling of online risks such as cyberbullying and issues of digital divide. Meanwhile, beyond formal education, the task of cultivating digital citizenship in young people lies also in the hands of parents, whose parental strategies are inherently informal and more dispersed. Most parents take steps to encourage their children to act with civility online, and a recent survey found that in the UK parents prioritize cultivating character and virtues (44\%) over trying to teach children about the consequences of their online actions (27\%) or making rules $(19 \%)$ (Harrison \& Polizzi, 2021). Parents are often regarded as primarily responsible for educating their children about how to minimalize the risks and maximize the opportunities of being online. This article, however, is primarily concerned with how schools and teachers approach DCE. This is because we believe that our study can be particularly helpful for educators in terms of developing a planned and reflective approach to digital citizenship, one that should be embedded more systematically within formal education in ways that are underpinned by moral theory. 
In the UK, most schools offer some form of DCE through assemblies, Personal, Social, Health Education (PSHE), Citizenship and Computing classes, and through advice and communications addressed to parents. In some cases, these activities can be broadly classified against one of the three prominent moral theories outlined above. For example, banning phones in classrooms or implementing codes of conduct for smartphone use might be considered deontological in nature, since these strategies rely on adults instructing children to respect rules (Diamantes, 2010; Tandon et al., 2020). What is not clear, however, is whether or how these rules influence young people's moral decision making when they interact online - do these rules register and matter to them? Likewise, some approaches that schools follow are more utilitarian (Stauffer et al., 2012) - these include, for instance, showing students films about the effects of cyberbullying or sexting. These approaches aim at providing young people with an ethical knowhow derived from developing an empathetic understanding of the negative consequences of online interactions. Again, little is known, however, about the extent to which these kinds of interventions are effective in shaping adolescents' moral decision making online. Increasingly, schools are adopting strategies that promote character education in line with neo-Aristotelian virtue ethics by encouraging adolescents to engage in conversations about the qualities necessary for using digital technologies as citizens of the digital age. For example, international government bodies such as the Council of Europe (2019), as well as international organizations like Common Sense Media (James et al., 2019) have provided useful resources to promote both a character and a competencies approach to digital citizenship education. Nevertheless, there is little evidence about whether or how these activities are effective in informing the moral decisions that young people make in their everyday online interactions.

In reality, many schools and educators develop approaches that combine deontological, utilitarian and virtue ethical strategies, but few, arguably, do so in ways that are conscious of these underlying moral theories (Harrison, 2021). Further, the impact of these strategies on reducing online incivility and abuse is largely unknown. Although evaluations of educational interventions are important, we argue that trials that assess the impact of such interventions equate with putting the cart before the horse. Rather, it is essential to first understand how adolescents make moral decisions online, with a view to then informing how schools and educators might draw on different moral theories. This is why the research that we present here is not concerned with which educational strategies informed by deontological, utilitarian or virtue ethics work best. By contrast, we are interested in which of these theories most underpins adolescents' moral thinking and actions when faced with an online dilemma. This, in turn, may inform those tasked with implementing policies and strategies designed to reduce online incivility.

\subsection{The present study}

This study was focused on answering the following research questions: 
RQ1: What moral decisions do 13-16 year-olds in England make when interacting with others on social media, and particularly in relation to issues of incivility and abuse?

RQ2: To what extent do their moral decisions align with deontological, utilitarian or virtue ethical theories?

\section{Methods}

As we began our study our hypothesis was that, when faced with an online dilemma, the decisions that 13-16 year-olds make are guided primarily by their perceptions of the rules behind or likely consequences of their actions, with character virtues informing, to some extent, their decisions. To answer RQs1 and 2 above, a survey, which was considered ideal for capturing patterns across a large sample of adolescents, was designed and administered by the research team among 13-16 year-olds in England. After reviewing relevant literature, a self-report questionnaire was first designed and piloted through cognitive interviews with four 14-15 year-olds. The interviews, along with feedback on the questionnaire from three secondary school teachers, led to minor adjustments to the questions.

\subsection{Measures}

The final version of the questionnaire included:

i) Socio-demographic questions: The first three questions asked adolescents about their age, gender and time spent on social media in an ordinary day. The latter question, which was adapted from the Global Kids Online survey (2021), included eight responses ranging from "little or no time" to "more than 5 hours".

ii) Reactions, and reasons for reacting, to an abusive post on social media: The next question asked adolescents what they would do if they came across an abusive post on social media, sent by one of their classmates to someone else in their class, in which they were tagged. Adolescents were asked to provide one response out of eight options, ranging from "do nothing" along with morally disengaged reactions such as "forward it to others in my school" to morally engaged reactions, including, for instance, "send a nice message to the person insulted to check how they feel", "report it to the social media company", and "post my own comment that criticizes the original post". If they answered "do nothing" or "something else", which prompted them to provide an open-ended response, they were asked to go straight to the next section of the survey. If not, they were first asked a question exploring the reason either behind their morally disengaged reactions (e.g., "because insulting posts are normal on social media") or behind their morally engaged reactions. In the latter case, responses included three deontological reasons (e.g., "because of the rules of the social media company"), three virtue-based reasons (e.g., "because it is the kind/thoughtful thing to do") and three utilitarian reasons (e.g., "because I might be punished if I don't"). While acting on kind- 
ness can be seen as a condition for the utilitarian project of promoting flourishing and happiness (see, for example, Mill, 1998), it was classified here, in line with Aristotelian virtue ethics, as a form of action that is primarily grounded in kindness as a character virtue. Meanwhile, whilst some would frame individuals' worries about punishment as self-serving and concerned primarily with politics rather than morality (see, for example, Binder, 2002), these were classified here as utilitarian because of their consequentialist nature.

In the limitations section of the paper below we outline the principal concerns about the validity and reliability of the measures. These primarily relate to issues of i) self-deception, 2) social desirability, and 3) self-confirmation bias due to the survey being self-report. Further questions on 1) the qualities that participants most want their friends to show on social media, 2) what qualities they think their friends show the least on social media, and 3) who taught them how to use social media wisely, were included in the survey but are not reported here. The findings from these measures can be found in Harrison \& Polizzi (2021).

\subsection{Participants}

Both convenience and purposive sampling was used to recruit eight secondary schools in England from 15 schools that were initially contacted through previous contacts known to the researchers, with a view to maximizing diversity in terms of 1) geographical location and 2) type of school - i.e., academy (independent, statefunded), community (run by local authorities) or Catholic. The questionnaire, which the schools administered among their students in Years 9, 10 and 11 between September and November 2020, was offered in two formats: online through Qualtrics, and via hard copy.

Whilst the original sample included 2067 responses, the final sample consisted of 1947 responses, as 120 responses were excluded due to missing data in all the self-reported measures beyond the socio-demographic questions. Table 1 provides an overview of the sample. $32 \%$ of the sample were 13 years old, $38 \%$ were 14 years old, $25 \% 15$ years old and 5\% 16 years old. 52\% of the participants were male and $46 \%$ female. The total number of responses under "age" and "gender" in the table does not add up to the number of valid responses to the survey (i.e., 1947) because of missing responses. Meanwhile, the percentages add up to 100 since they refer to the number of participants who did report their age and gender.

\subsection{Data analysis}

Once the data was cleaned and organized using Excel, it was imported into, and analyzed on, SPSS (version 22). First, descriptive analysis was performed to examine frequencies and distributions in relation to each of the measures above. When cross-tabulating the data by participants' age and gender and by time spent on social media, chi-square tests at $95 \%$ confidence level were performed to test for association. In addition, we used a binary logistic regression employing a .05 criterion of 
Table 1 Overview of the Sample

\begin{tabular}{ll}
\hline Participants & No. (\%) \\
\hline Age & \\
13 & $618(32 \%)$ \\
14 & $712(38 \%)$ \\
15 & $481(25 \%)$ \\
16 & $90(5 \%)$ \\
Gender & \\
Male & $991(52 \%)$ \\
Female & $867(46 \%)$ \\
Other & $30(2 \%)$ \\
Format used & \\
Online & $955(49 \%)$ \\
Hard copy & $992(51 \%)$ \\
\hline
\end{tabular}

statistical significance in order to test the association between adolescents' age, gender and time spent on social media and their selection of morally engaged reactions. Finally, participants' open-ended responses were examined by generating word clouds on NVivo (version 12), which were used to identify patterns across participants' responses and the key terms that they used.

\subsection{Ethical considerations}

The study was approved by the Ethics Committee of the University of Birmingham. All participants were fully informed about the purpose of the research and given the opportunity to withdraw at any point during the completion of the questionnaire. Prior to administering the survey, schools were sent an information sheet along with an opt-out consent form for those parents who did not wish for their children to take part in the survey.

\section{Results}

This section describes the findings from the survey. All chi-square test results reported below are statistically significant $(p<.05)$. All percentages in the charts have been rounded to the nearest whole number.

\subsection{Adolescents' reactions to an abusive post on social media}

As shown in Fig. 1, the reaction that most adolescents aged 13-16 reported having in response to coming across an abusive post on social media was "do nothing" ( $21 \%$ ), followed by "send a nice message to the person insulted to check how they feel" (19\%), then "tell my friend to stop tagging me in such messages" (17\%), and 


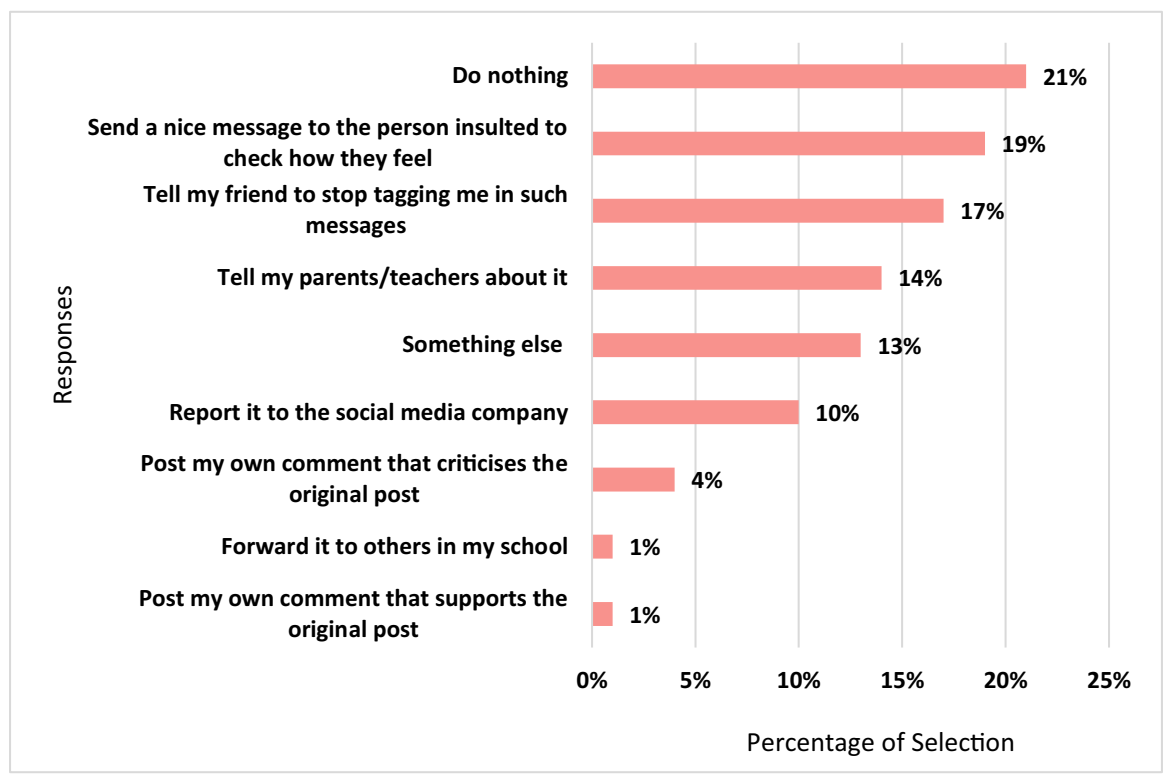

Fig. 1 Adolescents' Reactions to an Abusive Post on Social Media

then "tell my parents/teachers about it" (14\%). Most of those who chose "something else" (13\%) reported in their open-ended responses that they would react by combining responses, thus having more than one reaction, such as reporting the abusive post to parents or teachers before sending a nice message to the person insulted, or before asking their friend to stop tagging them in their posts.

Interestingly, adolescents' reactions differed by age group $\left[X^{2} \quad(24\right.$, $N=1843)=52.189, p<.01]$. More specifically, 13 year-olds were both the most likely to "send a nice message to the person insulted" (23\%) and the least likely to "do nothing" (17\%). By contrast, 15 year-olds were both the most likely to "do nothing" (24\%) and, together with 16 year-olds, the least likely to "send a nice message to the person insulted" (16\% each). Similarly, when it comes to gender, adolescents' reactions were also different $\left[X^{2}(8, N=1805)=110.46, p<.01\right]$. Compared to their male counterparts, female adolescents were more likely to choose the following reactions: "report it to social media company" (13\% versus $9 \%$ ), "send a nice message to the person insulted to check how they feel" (22\% versus $17 \%)$ and "tell my parents/teachers about it" (22\% versus $9 \%)$. By contrast, male adolescents were more likely to choose "post my own comment that criticizes the original post" (5\% versus $3 \%)$ and "do nothing" (26\% versus $15 \%)$.

Once reactions were grouped (Fig. 2) into either "morally disengaged reactions" (including "post my own comment that supports the original post", "forward it to others in my school" and "do nothing") or "morally engaged reactions" (including all other responses except "something else"), what stood out is that most adolescents chose morally engaged reactions (74\%) as opposed to morally disengaged reactions (26\%). Also, what Fig. 2 shows is that, as their age 


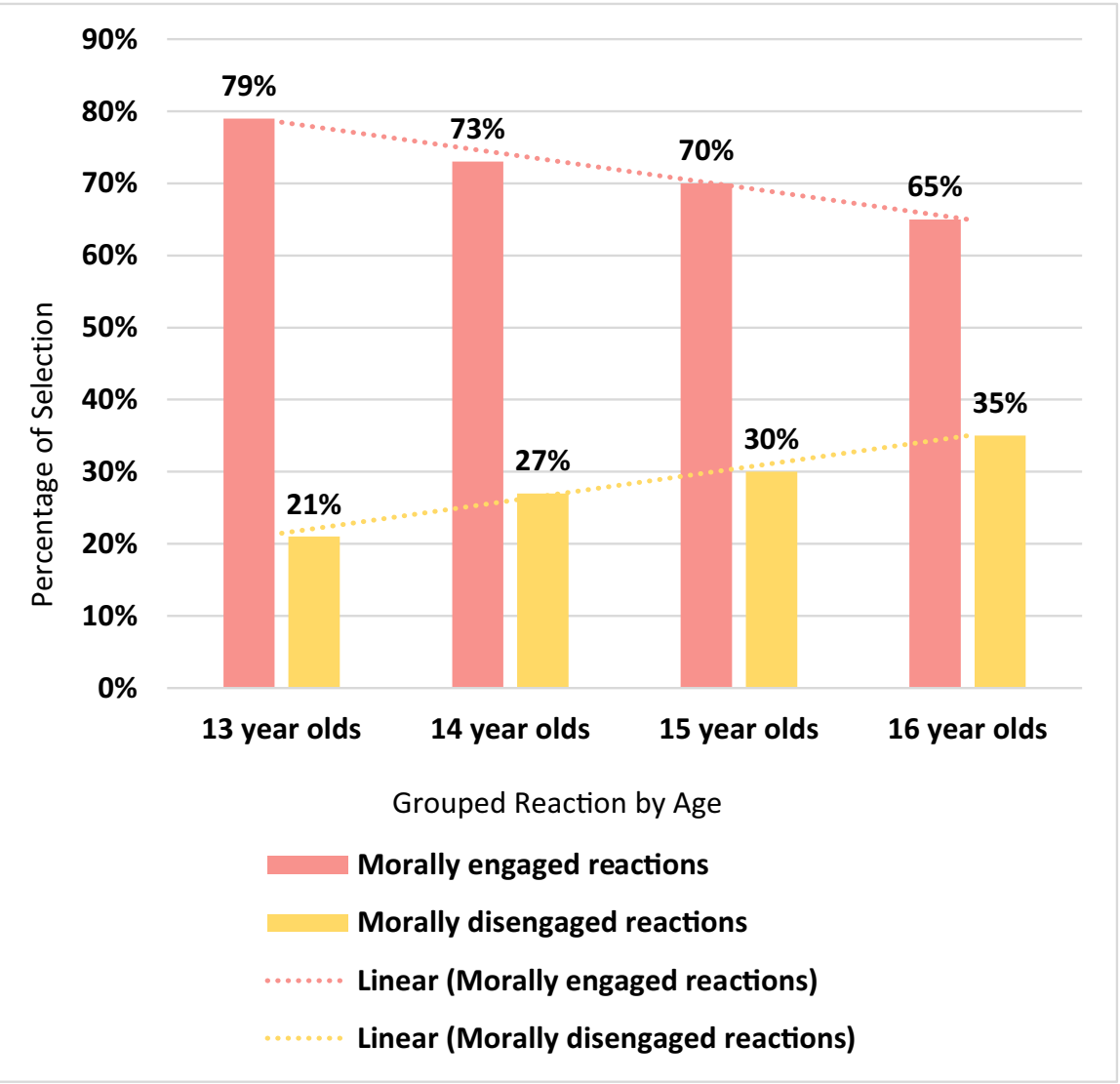

Fig. 2 Adolescents' Morally Engaged Reactions and Morally Disengaged Reactions by Age

increases, they become less likely to have morally engaged reactions (79\% at the age of 13 versus $65 \%$ at the age of 16) and more likely to have morally disengaged reactions $(21 \%$ at the age of 13 versus $35 \%$ at the age of 16$)$.

A binary logistic regression was carried to test the association between participants' age, gender and time spent on social media and their selection of a morally engaged reaction. The results evidenced a significant association between the variables and the outcome X2 $(3, N=1553)=94.923, p<.001$. Employing a .05 criterion of statistical significance, gender, time spent on social media and age had significant partial effects. As captured by Table 2, the odds ratio for gender indicates that when holding all other variables constant, females are 2.7 times more likely to choose a morally engaged reaction (once interacting with an abusive post) than males. Inverting the odds ratio for age and time spent on social media reveals that for each one-point increase on the eight-point time scale there are approximately $15 \%$ less chances of engaging in moral reactions. Similarly, 
Table 2 Association Between Participants' Age, Gender and Time Spent on Social Media and Their Selection of a Morally Engaged Reaction

\begin{tabular}{lllllll}
\hline & \multicolumn{7}{l}{ Variables in the Equation } \\
\cline { 2 - 7 } & \multicolumn{7}{c}{$\mathrm{B}$} & S.E. & Wald & $\mathrm{df}$ & Sig. \\
\hline Time & -.169 & .029 & 34.352 & 1 & .000 & .844 \\
Age & -.225 & .069 & 10.532 & 1 & .001 & .799 \\
Gender & 1.013 & .129 & 62.107 & 1 & .000 & 2.754 \\
Constant & 1.924 & .212 & 82.698 & 1 & .000 & 6.852 \\
\hline
\end{tabular}

for one unit increase in the four-point age scale there are approximately $20 \%$ less chances of engaging in a moral reaction.

\subsection{Reasons behind adolescents' reactions}

In total, as shown in Table 3, the reasons that most adolescents chose in support of their morally engaged reactions were virtue-based (68\%) as distinct from utilitarian $(21 \%)$ or deontological $(11 \%)$. More precisely, the reason that most adolescents chose was "because it is the kind/thoughtful thing to do" (37\%), followed by $25 \%$ who chose "because it is the just/fair thing to do", followed, in turn, by $13 \%$ who chose "because the same thing might happen to me". Their grouped reasons differed by gender $[X 2(2, N=992)=5.64, p<.05]$. Female adolescents were more likely to choose deontological reasons than their male counterparts (13\% versus $8 \%)$, with $7 \%$ choosing "because of the rules of the social media company" as opposed to $5 \%$ of male participants. By contrast, while the extent to which both females and males

Table 3 Adolescents' Reasons Behind their Morally Engaged Reactions

\begin{tabular}{lll}
\hline Reasons & Count & Column N \% \\
\hline Virtue-based & & \\
Because it is the kind/thoughtful thing to do & 379 & $37 \%$ \\
Because it is the just/fair thing to do & 258 & $25 \%$ \\
Because it is the brave/courageous thing to do & 59 & $6 \%$ \\
Total & 739 & $68 \%$ \\
Utilitarian & & \\
Because the same thing might happen to me & 128 & $13 \%$ \\
Because I might be punished if I don't & 43 & $4 \%$ \\
Because I might be criticised for doing otherwise & 43 & $4 \%$ \\
Total & 171 & $21 \%$ \\
Deontological & & \\
Because of the rules of the social media company & 65 & $6 \%$ \\
Because of my school's rules & 26 & $3 \%$ \\
Because of my parents' rules & 21 & $2 \%$ \\
Total & 112 & 1022 \\
Sum of totals & $100 \%$ \\
\hline
\end{tabular}


chose utilitarian reasons was similar (17\% each), male adolescents were more likely to choose virtue-based reasons than their female counterparts ( $75 \%$ versus $70 \%$ ). This includes $38 \%$ of males who chose "because it is the kind/thoughtful thing to do" as opposed to $34 \%$ of their female counterparts.

Once adolescents' reasons were matched with their reactions, what stood out was that most adolescents who would react to an abusive post on social media by "send[ing] a nice message to the person insulted" justified this reaction by choosing the reason "because it is the kind/thoughtful thing to do" (75\%). This is followed by $27 \%$ of adolescents choosing this reason to justify, rather, the fact that they would "report [the abusive post] to the social media company". By contrast, most adolescents who would react to an abusive post on social media by "post[ing] their own comment that criticizes the original post" justified this reaction by choosing the reason "because it is the just/fair thing to do" (44\%). This was followed by $35 \%$ choosing this reason to justify the fact that they would "tell their parents/teachers about it". Meanwhile, among those few adolescents who would react to an abusive post on social media by either forwarding it to others in school (1\%) or by posting their own comment in support of the original post (1\%), most of them (i.e., 29\% and 33\%, respectively) justified either of these morally disengaged reactions by choosing the reason "because in general I find these posts funny".

\section{Discussion}

In this article we have presented data that shows what moral decisions 13-16 yearolds in England make when presented with an issue of incivility on social media (RQ1), and the extent to which their decisions align with deontological, utilitarian or virtue ethical theory (RQ2). The purpose of this research was to reflect on how approaches to digital citizenship education might be adapted to take account of moral theory. In this section, the findings reported above are discussed in relation to the broader literature, with emphasis on their implications for research and practice.

Significantly, we found that most participants, if they were tagged into an abusive social media post about someone in their class, would be more likely to choose morally engaged reactions (74\%) rather than morally disengaged reactions $(26 \%)$. This finding is based on a classification of participants' reactions that is grounded in Bandura's (1999) theory of moral disengagement. The present research builds on a few studies that have drawn on this theory to explore the extent to which users make morally engaged or disengaged decisions online (e.g., D'Errico \& Paciello, 2018; Ge, 2020; Kyriacou \& Zuin, 2018; Price et al., 2013). These studies have argued that using social media within different contexts (from discussing climate change or migration to witnessing to cyberbullying) contribute primarily to forms of moral disengagement than of moral engagement. By contrast, as found here, the fact that almost eight in ten adolescents aged 13-16 in England would react to an abusive post in ways that, when grouped together, are morally engaged, is both reassuring and promising. It is of note, however, that their most reported individual reaction was in fact to "do nothing" (21\%), which was classified as form of moral disengagement. This reaction, which has been widely discussed in the literature on moral 
reasoning and (in)action (see, for example, Abbot \& Cameron, 2014), is an example of passive bystander behavior; one that is not necessarily hostile (as in posting a comment on social media that reinforces an abusive post) but is still "negative" since it contributes to spread of online abuse (Machakova et al., 2018). Indeed, as remarked by DeSmet et al. (2015), "passive bystanding provides positive feedback to the bully, since the bully and victim may consider this as a silent form of approval of the bullying" (p. 399). What we were not able to tell from the survey is what motivates adolescents to do nothing when coming across an abusive post on social media. This is a question that requires further research, as does whether users might do nothing as a way of perpetuating incivility. Nevertheless, what is clear from the literature is that, because of the nature of the digital environment and the affordances of the Internet, bystander behavior might be more extreme or likely online than offline (e.g., Runions \& Bak, 2015). Witnesses to online abuse might be less likely to respond positively because the Internet is subject to reduced rules, monitoring and regulation, which means that online incivility may be more accepted online than offline. In addition, communicating at a distance reduces sensitivity towards victims. That is, because of limited synchronous feedback or visual clues (Suler, 2004), witnesses to online abuse are less likely to develop an emotional response that might make them change their behavior. Furthermore, a decrease in "social presence" within online settings can reduce empathy (Malti et al., 2010).

Not only was adolescents' most reported individual reaction to "do nothing" when coming across an abusive post, but we also found that, as age increases, they are less likely to have morally engaged reactions (79\% at the age of 13 versus $65 \%$ at the age of 16) and more likely to have morally disengaged reactions, including passive behavior, such as doing nothing, as well as reinforcing hostile behavior, such as posting their own comment in support of the abusive post or forwarding this to others (21\% at the age of 13 versus $35 \%$ at the age of 16). This finding suggests that age plays an important role in the context of moral development. Relatedly, it echoes previous research conducted by the Jubilee Centre for Character and Virtues (Arthur et al., 2015) arguing that adolescents, especially when turning 14 and 15 , tend to experience a dip in their moral development. This "moral dip" was also noted in some of the experiments conducted by Kohlberg (e.g., Kohlberg \& Kramer, 1969). It is not clear why this dip occurs, but it has been suggested that adolescents lose some of their moral compass once they question their upbringing (Arthur et al., 2015).

Another key finding that emerged from the survey is that adolescents in England value the importance of using digital technologies in ways that are virtuous. In total, the explanations that most adolescents chose in support of their morally engaged reactions were virtue-based $(68 \%)$ as distinct from utilitarian $(21 \%)$ or deontological $(11 \%)$. As noted earlier when reviewing the literature, this is an area that has remained under-studied. The closest study to the present one that we could find was conducted by Yoon in 2011. The current study brings this research up to date and was conducted with a larger sample (1947 participants compared to 111). Yoon's (2011) study was also conducted in South Korea rather than England, and with university students rather than 13-16 year-olds. Yoon found that his participants' moral judgments and behavior align with the five moral philosophies in his investigation 
(i.e., justice, relativism, egoism, deontology and utilitarianism). This finding confirms what our study found: adolescents justify their moral decisions online in ways that resonate with different moral theories, including, primarily, virtue ethics. In the Yoon study, university students' moral decision making aligns predominantly with principles of justice. To the extent that justice is widely considered a moral virtue (Jubilee Centre for Character and Virtues, 2017), his findings mirror ours. Yoon also found that his participants' moral judgements incorporate elements of deontology, but only in the context of some moral dilemmas and not others. This finding has implications for the present research as the dilemma used (deciding what to do when coming across an abusive post on social media) may have favored responses that may be more virtuous or utilitarian. While we believe that this was not necessarily the case, in future research it would be good to include multiple dilemmas to test this claim. What is also not known from the present or from Yoon's research is how explicitly or implicitly these moral theories align with users' moral decision making online. That is, do they operate somewhat subconsciously as part of users' moral schemas, or more in the foreground? This is a complex question that is ripe for further research.

What our study also found is that, when holding other variables constant, female adolescents aged 13-16 in England are 2.7 times more likely to choose a morally engaged reaction in response to online abuse on social media than their male counterparts. On the one hand, this finding resonates with previous literature that has argued that male users are not as morally engaged on social media as female users (e.g., Jackson et al., 2008). On the other hand, what this study adds is that, while male adolescents were found to be more likely than female adolescents to choose virtue-based reasons ( $75 \%$ versus $70 \%$ ), female adolescents were more likely than their male counterparts to choose deontological reasons (13\% versus $8 \%$ ), with $7 \%$ choosing "because of the rules of the social media company" as opposed to $5 \%$ of male participants. This finding requires further research into whether gender differences apply to how adolescents justify their moral decisions online. But insofar as both male and female adolescents were found to largely favor virtue ethical (over deontological and utilitarian) reasons for responding to online incivility, we argue that more attention could be paid, in the context of formal education, to the provision of virtue-based character education.

This form of education has been somewhat neglected (Harrison, 2021) and would demand both school and classroom activities that prioritize character, virtue and the development of cyber-wisdom as part of digital citizenship education (Harrison, 2016a; Harrison \& Polizzi, 2021). This approach is timely and promising as there has been a renaissance of research into character and the virtue of wisdom in recent years, including an influential paper that establishes a common wisdom model (Grossmann et al., 2020) and a paper on phronesis (i.e., practical wisdom) as a multicomponent construct (e.g., Darnell et al., 2019). In other words, of particular importance will be to educate adolescents though character education that frames moral decision making in ways that are grounded primarily in Aristotelean virtue ethics, which prioritizes autonomous decision making. This has significant implications for how schools and educators develop and deliver digital citizenship education in ways that are underpinned by moral theory, not just among 13-16 years-old 
but among pupils of all ages. The findings of our research provide evidence that it would be beneficial for research to test interventions that place the cultivation of character virtues at the heart of digital citizenship education delivered formally across different schools and in-class activities. We believe that it is important to take such an evidence-based approach to bolster not only widely adopted frameworks for teaching digital citizenship (e.g., Ribble, 2007) but also wider policy developments around this form of education and the subjects through which, in the case of the national curriculum for England, it is generally taught (i.e., PSHE, Citizenship and Computing) (Polizzi \& Harrison, 2020).

\section{Limitations}

We believe that our research has meaningful implications and addresses a lacuna in the field, but it is not without limitations. Firstly, the current study presents limitations in relation to the sample and measures used. The fact that the sampling strategy was non-probabilistic means that the data is likely to contain some bias. Relatedly, the findings cannot be reliably generalized to the broader population. Schools, furthermore, were recruited only across England, and not from across the UK or globally. Finally, all the measures used were based on self-reporting, which may have caused issues of self-deception, social desirability and self-confirmation bias. This means that participants may have provided responses that were not accurate, or that were dictated by a desire to be viewed favorably or to please the researcher (Weber \& Cook, 1972). Given the moral dilemma used in the survey, which related to someone being unkind online, it is also possible that the survey favored responses that were more virtuous. For this reason, we cannot state that morally engaged, and specifically virtue-based, responses are most likely for all the moral dilemmas that 13-16 year-olds might face online. This is why the methodology used in this study could be strengthened in future research by presenting participants with multiple dilemmas. Furthermore, the possibility that adolescents' moral decisions are independent or positively related was not examined, which is why further analysis is needed to explore the relationships between their reasons. Finally, we were unable to capture the reasons why most participants chose 'do nothing', since we did not ask them this question.

\section{Conclusion}

For many children the Internet has improved their lives; it has offered them opportunities for entertainment, learning, socialization and participation in society. But it has also exposed them to risks, including, most prominently, privacy constraints, misinformation, inappropriate content and online abuse such as cyberbullying. In an age in which children are both the Internet's most vulnerable users and its pioneers it is important to understand how the technology contributes to and/or diminishes human flourishing. The task of promoting Internet safety and human flourishing online is an important one that lies in the hands of 
multiple stakeholders, not just children and their parents but also educators and, when it comes to managing the digital environment, policymakers and Internet corporations. This is why promoting digital citizenship education is one of the most pressing global challenges of the digital age (Burns \& Gottschalk, 2020, p. 46).

The key findings from the present study that should inform these stakeholders suggest that 1) 13-16 year-olds prioritize morally engaged decisions when presented with a dilemma associated with (in)civility online, and 2) their moral reactions are more likely to be informed by virtue ethical moral thinking rather than deontological or utilitarian thinking. These findings invite researchers to look more closely at the importance of virtue ethics in shaping moral behavior online. Furthermore, they invite policymakers, educators and parents as well as those who design social media platforms to think about how to prioritize young people's ability to develop and deploy virtues in the context of their online interactions, and in synergy with both utilitarian and deontological principles. When it comes to formal education, the next key consideration is how the findings of this study might inform revised digital citizenship curricula and teaching resources. Relatedly, while intervention research is needed on this topic, a pragmatic and non-reductionist approach to digital citizenship education is necessary, one that may enable educationalists to develop strategies informed by an understanding of how adolescents make moral decisions online. Meanwhile, more research is needed into why young people experience a moral dip as part of their development.

Acknowledgements This study was conducted as part of the Jubilee Centre for Character and Virtues' 'Celebration Britain' programme, funded by the Templeton Foundation.

\section{Declarations}

We confirm that no financial interest or benefit has arisen from the direct application of this research.

Open Access This article is licensed under a Creative Commons Attribution 4.0 International License, which permits use, sharing, adaptation, distribution and reproduction in any medium or format, as long as you give appropriate credit to the original author(s) and the source, provide a link to the Creative Commons licence, and indicate if changes were made. The images or other third party material in this article are included in the article's Creative Commons licence, unless indicated otherwise in a credit line to the material. If material is not included in the article's Creative Commons licence and your intended use is not permitted by statutory regulation or exceeds the permitted use, you will need to obtain permission directly from the copyright holder. To view a copy of this licence, visit http://creativecommons.org/licen ses/by/4.0/.

\section{References}

Abbot, N., \& Cameron, L. (2014). What makes a young assertive bystander? The effect of intergroup contact, empathy, cultural openness, and in-group bias on assertive bystander intervention intentions. Journal of Social Issues, 70(1), 167-182. https://doi.org/10.1111/josi.12053.

Anscombe, G. E. M. (1958). Modern moral philosophy. Philosophy, 33(124), 1-19. https://www.jstor. org/stable/3749051 
Arthur, J., Kristjánsson, K., Walker, D., Sanderse, W., \& Jones, C. (2015). Character education in UK schools: Research report. Jubilee Centre for Character and Virtues, University of Birmingham. https://www.jubileecentre.ac.uk/userfiles/jubileecentre/pdf/Research\%20Reports/Character_Educa tion_in_UK_Schools.pdf

Bandura, A. (1999). Moral disengagement in the perpetration of inhumanities. Personality and Social Psychology Review, 3(3), 193-209. https://doi.org/10.1207/s15327957pspr0303_3.

Bandura, A. (2001). Social cognitive theory: An agentic perspective. Annual Review of Psychology, 52(1), 1-26. https://doi.org/10.1146/annurev.psych.52.1.1.

Bartels, D., \& Pizarro, D. (2011). The mismeasure of morals: Antisocial personality traits predict utilitarian responses to moral dilemmas. Cognition, 121(1), 154-161. https://doi.org/10.1016/j.cognition. 2011.05.010.

Benzmiller, H. (2013). The cyber-samaritans: Exploring criminal liability for the innocent bystanders of cyberbullying. Northwestern University Law Review, 107(2), 927-962 https://scholarlycommons. law.northwestern.edu/nulr/vol107/iss2/17.

Binder, G. (2002). Punishment theory: Moral or political? Buffalo Criminal Law Review, 2(2), 321-372. https://doi.org/10.1525/nclr.2002.5.2.321.

Burns, T., \& Gottschalk, F. (2020). Educational research and innovation. Education in the Digital Age: Healthy and Happy Children. OECD

Cocking, D., \& van den Hoven, J. (2018). Evil online. Wiley Blackwell

Council of Europe. (2019). Digital citizenship education handbook. https://rm.coe.int/digital-citizenshipeducation-handbook/168093586f

D'Errico, F., \& Paciello, M. (2018). Online moral disengagement and hostile emotions in discussions on hosting immigrants. Internet Research, 28(5), 1313-1335. https://doi.org/10.1108/ IntR-03-2017-0119.

Darnell, C., Gulliford, L., Kristjánsson, K., \& Paris, P. (2019). Phronesis and the knowledge-action gap in moral psychology and moral education: A new synthesis? Human Development, 62(3), 101-129. https://doi.org/10.1159/000496136.

DeSmet, A., Bastiaensens, S., Van Cleemput, K., Poels, K., Vandebosch, H., Cardon, G., \& De Bourdeaudhuij, I. (2015). Deciding whether to look after them, to like it, or leave it: A multidimensional analysis of predictors of positive and negative bystander behavior in cyberbullying among adolescents. Computers in Human Behavior, 57, 398-415. https://doi.org/10.1016/j.chb.2015.12.051.

Diamantes, T. (2010). Recent court rulings regarding student use of cell phones in today's schools. Education, 131(2), 404-406.

Foot, P. (1978). Virtues and vices. Blackwell.

Ge, X. (2020). Social media reduce users' moral sensitivity: Online shaming as a possible consequence. Aggressive Behavior, 46(5), 359-369. https://doi.org/10.1002/ab.21904.

Global Kids Online. (2021). Quantitative tools. http://globalkidsonline.net/tools/survey/

Griffith, P., Norman, W., O'Sullivan, C., \& Ali, R. (2011). Charm offensive cultivating civility in 21st century Britain. The Young Foundation. https://youngfoundation.org/wp-content/uploads/2012/10/ Charm-Offensive-October-2011.pdf

Grossmann, I., Weststrate, N. M., Ardelt, M., Brienza, J. P., Dong, M., Ferrari, M., \& Fournier, ... \& Vervaeke, J. (2020). The science of wisdom in a polarized world: Knowns and unknowns. Psychological Inquiry, 31(2), 103-133. https://doi.org/10.1080/1047840X.2020.1750917.

Haidt, J., \& Joseph, C. (2008). The moral mind: How five sets of innate intuitions guide the development of many culture-specific virtues, and perhaps even modules. In P. Carruthers, S. Laurence, \& S. Stich (Eds.), Evolution and cognition: The innate mind. Vol. 3. Foundations and the future (pp. 367-391). Oxford University Press.

Harrison, T. (2016a). Cultivating cyber-phronesis: A New educational approach to tackle cyberbullying. Pastoral Care in Education: An International Journal of Personal, Social and Emotional Development, 34(4), 232-244. https://doi.org/10.1080/02643944.2016.1202307

Harrison, T. (2016b). Virtuous reality: Moral theory and research into cyber-bullying. Ethics and Information Technology, 17(4), 275-283. https://doi.org/10.1007/s10676-015-9382-9

Harrison, T. (2021). Thrive: How to cultivate character so your children can flourish online. Robinson

Harrison, T. \& Polizzi, G. (2021). A cyber-wisdom approach to digital citizenship education: Insights from adolescents and parents. Jubilee Centre for Character and Virtues, University of Birmingham. https://www.jubileecentre.ac.uk/userfiles/jubileecentre/pdf/news/ACyber-WisdomApproachtoDigi talCitizenshipEducation_Final.pdf 
Jackson, L. A., Zhao, Y., Qiu, W., Kolenic, I. I. I., Fitzgerald, H. E., Harold, R., \& von Eye, A. (2008). Cultural differences in morality in the real and virtual worlds: A comparison of Chinese and U.S. youth. Cyber-Psychology \& Behavior, 11(3), 279-286. https://doi.org/10.1089/cpb.2007.0098.

James, C., Weinstein, E., \& Mendoza, K. (2019). Teaching digital citizens in today's world: Research and insights behind the Common Sense K-12 Digital Citizenship Curriculum. Coemon Sense Media. https://d1e2bohyu2u2w9.cloudfront.net/education/sites/default/files/tlr_component/common_ sense_education_digital_citizenship_research_backgrounder.pdf

John, A., Glendenning, A. C., Marchant, A., Montgomery, P., Stewart, A., Wood, S., et al. (2018). Selfharm, suicidal behaviours, and cyberbullying in children and young people: Systematic review. Journal of Medical Internet Research, 20(4), e129. https://doi.org/10.2196/jmir.9044.

Jubilee Centre for Character and Virtues. (2017). A framework for character education in schools. University of Birmingham. https://www.jubileecentre.ac.uk/framework

Kohlberg, L., \& Kramer, R. (1969). Continuities and discontinuities in childhood and adult moral development. Human Development, 12(2), 3-120. https://doi.org/10.1159/000270857.

Kristjánsson, K. (2015). Aristotelian character education. Routledge.

Kyriacou, C., \& Zuin, A. (2018). Cyberbullying bystanders and moral engagement: A psychosocial analysis for pastoral care. Pastoral Care in Education: An International Journal of Personal, Social and Emotional Development, 36(2), 9-111. https://doi.org/10.1080/02643944.2018.1453857.

LaFollette, H., \& Persson, I. (Eds.). (2013). The Blackwell guide to ethical theory (2nd ed.) Wiley-Blackwell.

Lievens, E. (2011). Risk-reducing regulatory strategies for protecting minors in social networks. Strategy for Telecommunications, Information and Media, 13(6), 43-54. https://doi.org/10.1108/1463669111 1174252.

Livingstone, S., Mascheroni, G., \& Staksrud, E. (2018). European research on children's internet use: Assessing the past and anticipating the future. New Media and Society, 20(3), 1103-1122. https:// doi.org/10.1177/1461444816685930

Lyu, H. (2012). Internet policy in Korea: A preliminary framework for assigning moral and legal responsibility to agents in internet activities. Government Information Quarterly, 29(3), 394-402. https:// doi.org/10.1016/j.giq.2011.12.008.

Machackova, H., Dedkova, L., Sevcikova, A., \& Cerna, A. (2018). Bystanders' supportive and passive responses to cyberaggression. Journal of School Violence, 17(1), 99-110. https://doi.org/10.1080/ 15388220.2016.1222499.

Malti, T., Gasser, L., \& Gutzwiller-Helfenfinger, E. (2010). Children's interpretive understanding, moral judgments, and emotion attributions: Relations to social behaviour. British Journal of Developmental Psychology, 28, 275-292. https://doi.org/10.1348/026151009x403838.

Mill, J. S. (1998). On liberty and other essays. Oxford University Press.

Ofcom. (2020). Children and parents: Media use and attitudes report 2019. https://www.ofcom.org. uk/_data/assets/pdf_file/0023/190616/children-media-use-attitudes-2019-report.pdf

Patchin, J. W., \& Hinduja, S. (2015). Measuring cyberbullying: Implications for research. Aggression and Violent Behavior, 23, 69-74. https://doi.org/10.1016/j.avb.2015.05.013.

Polizzi, G. (2020). Digital literacy and the national curriculum for England: Learning from how the experts engage with and evaluate online content. Computers \& Education, 152, 103859. https://doi. org/10.1016/j.compedu.2020.103859

Polizzi, G., \& Harrison, T. (2020). Integrating cyber-wisdom education into the school curriculum. Jubilee Centre for Character and Virtues, University of Birmingham. https://www.jubileecentre.ac.uk/ userfiles/jubileecentre/pdf/insight-series/GP_TH_IntegratingCyber-WisdomEducationintotheSch oolCurriculumFinal.pdf

Price, D., Green, D., Spears, B., Scrimgeour, M., Barnes, A., Geer, R., \& Johnson, B. (2013). A qualitative exploration of cyber-bystanders and moral engagement. Australian Journal of Guidance and Counselling, 24(1), 1-17. https://doi.org/10.1017/jgc.2013.18.

Reidenbach, R., \& Robin, D. (1990). Toward the development of a multidimensional scale for improving evaluations of business ethics. Journal of Business Ethics, 9(8), 639-653. https://doi.org/10.1007/ BF00383391.

Ribble, M. (2007). Digital citizenship in schools: Nine elements all students should know. International Society for Technology in Education

Runions, K., \& Bak, M. (2015). Online moral disengagement, cyberbullying, and cyber-aggression. Cyberpsychology, Behavior and Social Networking, 18(7), 400-405. https://doi.org/10.1089/cyber. 2014.0670. 
Selwyn, N., \& Aagaard, J. (2021). Banning mobile phones from classrooms-An opportunity to advance understandings of technology addiction, distraction and cyberbullying. British Journal of Educational Technology, 52(1), 8-19. https://doi.org/10.1111/bjet.12943.

Smith, P. K., \& Berkkun, F. (2017). How research on cyberbullying has developed. In C. Mc Guckin \& L. Corcoran (Eds.), Bullying and cyberbullying: Prevalence, psychological impacts and intervention strategies (pp. 11-27) Nova Science.

Stauffer, S., Heath, M., Coyne, S., \& Ferrin, S. (2012). High school teachers' perceptions of cyberbullying prevention and intervention strategies. Psychology in the Schools, 49(4), 352-367 https://eric.ed. gov/?id=EJ989962.

Suler, J. (2004). The online disinhibition effect. CyberPsychology and Behavior, 7(3), 321-326. https:// doi.org/10.1089/1094931041291295.

Tandon, P., Zhou, C., Hogan, C. M., \& Christakis, D. A. (2020). Cell phone use policies in US middle and high schools. JAMA Network Open, 3(5), e205183. https://doi.org/10.1001/jamanetworkopen. 2020.5183.

UK Government. (2019). Online harms white paper. https://assets.publishing.service.gov.uk/government/ uploads/system/uploads/attachment_data/file/973939/Online_Harms_White_Paper_V2.pdf

Vallor, S. (2016). Technology and the virtues: A philosophical guide to a future worth wanting. Oxford University Press.

Weber, S. J., \& Cook, T. D. (1972). Subject effects in laboratory research: An examination of subject roles, demand characteristics, and valid inference. Psychological Bulletin, 77(4), 273-295. https:// doi.org/10.1037/h0032351.

Whittaker, E., \& Kowalski, R. (2015). Cyberbullying via social media. Journal of School Violence, 14(1), 11-29. https://doi.org/10.1080/15388220.2014.949377.

Williams, B. (1985). Ethics and the limits of philosphy. Routledge.

World Wide Web Foundation. (2019). 30 years on, what's next \#ForTheWeb? https://webfoundation.org/ 2019/03/web-birthday-30/

Yoon, C. (2011). Ethical decision-making in the internet context: Development and test of an initial model based on moral philosophy. Computers in Human Behavior, 27(6), 2401-2409. https://doi. org/10.1016/j.chb.2011.08.007.

Publisher's note Springer Nature remains neutral with regard to jurisdictional claims in published maps and institutional affiliations. 